\title{
Bi Film-Video World High and Low
}

\section{Maria Pramaggiore}

To cite this article: Maria Pramaggiore (2001) Bi Film-Video World High and Low, Journal of Bisexuality, 2:2-3, 243-266, DOI: 10.1300/J159v02n02 17

To link to this article: https://doi.org/10.1300/J159v02n02_17

曲 Published online: 12 Oct 2008.

Submit your article to this journal

Џll Article views: 115

Citing articles: 2 View citing articles 줄 
Bi

Film-Video World

High and Low: Bisexual Women and Aesthetics in Chasirag sinougy

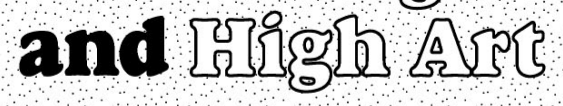

Maria Pramaggiore 


\section{(C) 2002 by The Haworth Press, Inc. All rights reserved.}

[Haworth co-indexing entry note]: "High and Low: Bisexual Women and Aesthetics in Chasing Amy and High Art." Pramaggiore, Maria. Co-published simultaneously in Journal of Bisexuality (Harrington Park Press, an imprint of The Haworth Press, Inc.) Vol. 2, No. 2/3, 2002, pp. 243-266; and: Bisexual Women in the Twenty-First Century (ed: Dawn Atkins) Harrington Park Press, an imprint of The Haworth Press, Inc., 2002, pp. 243-266. Single or multiple copies of this article are available for a fee from The Haworth Document Delivery Service [1-800-HAWORTH, 9:00 a.m. - 5:00 p.m. (EST). E-mail address: getinfo@ haworthpressinc.com]. 
SUMMARY. This essay examines two recent U.S. films that explicitly connect art and women's bisexuality: Kevin Smith's Chasing Amy (1997) and Lisa Cholodenko's High Art (1998). The affiliation between bisexuality and art reflects a paradox: an erotics of refusing distinctions, bisexuality acts as a metaphor for both the breakdown of sexual categories and the blending of high art and low entertainment. Yet bisexuals are subjects presumed to know; experimental, and, therefore, experienced, they are better equipped to make distinctions. In these films, one important aesthetic and sexual distinction revolves around the notion of the "real." [Article copies a vailable for a fee from The Haworth Document Delivery Service: 1-800-HAWORTH. E-mail address: <getinfo@haworthpressinc. com> Website: <http://www.HaworthPress.com> (C) 2002 by The Haworth Press, Inc. All rights reserved.]

In a March 2000 Sight and Sound essay entitled "Queer and Present Danger," B. Ruby Rich argues that the "moment" for New Queer Cinema has passed. She states that queer filmmaking has succumbed to the logic of the marketplace, becoming "just another niche market, another product line pitched at one particular type of discerning consumer" (24). "New Queer Cinema" is the term Rich herself coined more than a decade ago to describe a variety of non-mainstream queer filmmaking practices; its terminology hearkens back to the experimental, anti-establishment "New American Cinema" movement of the early 1960s. According to Rich, a spate of late 1990s films including Being John Malkovich (1999), The Talented Mr. Ripley (1999), and Boys Don't Cry (1999) offer proof that New Queer Cinema's sensibility has infiltrated the mainstream, for better and for worse.

If in fact New Queer Cinema has shifted from a community-based movement into a commercial, less overtly political venture, then I am interested in exploring the implications of this transition for bisexual representation. A marginalized identity and orientation within queer culture-a "niche market," if you will-bisexuality has been subject to the many of the same representational strategies and stereotyping that have characterized gay and lesbian representation. Those familiar representational devices include invisibility, hypersexualization, pathologization, and fetishization. Yet bisexual cinema has yet to make its mark in terms of representations of bisexuality or the development of a bisexual aesthetic, even within the rubric of New Queer Cinema. If, as Rich states, New Queer cinema is in "total meltdown" (22), then what are the implica- 
tions of this chaotic transition period: the mainstreaming of bisexualities along with homosexuality, or their further marginalization?

The current state of New Queer Cinema reflects the context for independent filmmaking in the US: by the late 1990s, "mainstream independent" routinely sought audiences and distributors at festivals like Sundance, a process that casts doubt on the notion that important distinctions remain between industry and independent films. As Rich implies, to be widely seen, independent filmmakers now depend upon the industry's perception of a niche market for their films and subject their work to profit-based calculations that cross the line between independence and industry.

Before addressing bisexual representation in four recent films, and, more specifically, the way women's bisexuality becomes the problem at the center of narrative and visual representation, I briefly lay some groundwork for a discussion of bisexual desire and narrative film. I then examine the connection between bisexuality and art forged in several recent films, a link that is most fully exploited in two films that focus on women's (bi)sexuality: Kevin Smith's Chasing Amy (1997) and Lisa Cholodenko's High Art (1998). The affiliation between bisexuality and art is related to anxieties associated with making distinctions, not only in terms of sexuality and gender, but in terms of cinema as well.

\section{FILM AND BISEXUAL EROTICS}

I have argued elsewhere that bisexualities are fluid erotics not dependent upon gender; they represent a refusal to choose between identification and desire (Pramaggiore, 1996, 274). Bisexualities "have it both ways," imagining and enacting relationships where identification with and desire for erotic object(s) are complementary rather than oppositional. I depart from Freud's well-known concept of a bisexual disposition, which is governed by the heterosexual imperative. Freud's construct describes humans as constitutionally male and female, each half of which desires its opposite. Freud believed that one dyad was repressed in the maturation process. Instead, I understand bisexuality as the availability of many positions in relation to sexual and gender difference-a stance toward which Freud seemed to be moving in his later work, according to Marjorie Garber and Jacqueline Rose (Garber, 1995, 182). According to Garber in Vice Versa: Bisexuality and the Eroticism of Everyday Life, Freud eventually saw bisexuality as "the unfixed nature of sexual identity and sexual object choice" (Garber, 1995, 182). 
Bisexuality involves attraction to, involvement with, and/or fantasies regarding persons across sexual and gender categories: sexual attraction and satisfaction may occur irrespective of gender and sexual difference or sameness. The dualism of heterosexual and homosexual discrimination-a bias, predisposition, or "bent" in favor of same- or other-sex partnerships-does not operate.

In popular cinema, the unfixed quality of bisexual desire can upset normative narrative arrangements that typically require sexual tension, conflict, and, ultimately, closure through coupling. In Bordwell, Staiger, and Thompson's frequently cited study of classical Hollywood cinema, a random sample of 100 films includes 85 that had romance as a "principal line of action" (Bordwell, Staiger, and Thompson, 1986, 16). Gay and lesbian narratives, and especially the coming-out plot, usually involve romance as well. Coming out is a sexual and psychological transition: the rejection of a straight identity and partners of the other sex after finding sexual satisfaction and emotional fulfillment with same-sex partners. In bisexual narratives, however, periods of "transition" offer little hope of standard forms of closure because choosing new sexual partners does not equate with a new, and presumably, final, sexual identity. Often, bisexuality is represented by omission and absence-a refusal to certify a sexual identity as either gay or straight, to cement a relationship with traditional signifiers of closure (sexual consummation, marriage, coming out). Rather than to proclaim and revel in a stable monosexual identity, a bisexual character accepts attraction to men and women and others as well as the more general unpredictability of desire.

Furthermore, that bisexual lack of commitment to consistently gendered or sexed object choices is associated with political insufficiencies and aesthetic excess. Bisexual unpredictability-often rendered as personal and political untrustworthiness and immaturity-is strongly associated with aesthetic discrimination (a heightened sensitivity to hierarchies of beauty and value).

Certainly these tropes contribute to stereotypes of gay and lesbian as well as bisexual characters. Consider the frequent associations of gay men with high art, especially opera. New Queer Cinema has addressed a number of narrative and cinematic blind spots by resisting and recasting conventions (that continue to flourish in popular representations), by consistently representing gay and lesbian sexuality in the context of community, and by moving beyond the first generation of coming-out narratives to provide a forum for the proliferation of diverse images. In New Queer Cinema, gay and lesbian relationships reveal new ways of 
constructing family and friendships; however, because bisexuality is assumed to be incompatible with commitment, it is the province of individuals without personal or political allegiances. Conventions such as bisexual political apathy and betrayal are sustained by such representations; sociologist Paul Rust's survey of lesbians includes some who consider bisexual women "political cowards" because of their sexuality (Rust, 1995, 49).

One result of the difficulties bisexual desire presents to mainstream and gay and lesbian filmmaking is that bisexual characters are as likely to show up in the former as the latter. Bisexual characters appear in Ang Lee's low-budget independent film The Wedding Banquet (1993), the most profitable film of 1993, and in two industry products, Three of Hearts (1993) and Threesome (1994). A potentially bisexual character even shows up on the small screen in the made-for-television movie Mary and Rhoda (2000), a Mary Richards-Rhoda Morgenstern reunion event. Mary's daughter Rose mentions a woman's name amidst a string of former boyfriends' names. By contrast, the only example of a New Queer Cinema film that features a bisexual protagonist is the late French filmmaker Cyril Collard's Savage Nights (1992).

The "problem" bisexuality poses-in political and narrative terms-is evident in mainstream and alternative representations, in industry and independent film, in high and popular discourses including Time magazine, television, film, and academia. Thus, the transition (or evolution) of New Queer Cinema from avant-garde to a mainstream "niche market" may not make much difference for bisexual representation: neither experimental nor conventional film has the "formula" for addressing the implications of a lack of coupled closure, or the sexual and gender indeterminacy associated with bisexual erotics. Furthermore, the peculiarities of each cinematic mode becomes harder to draw with any reliability in the current context, when, as Rich points out, distinctions are merely occasions to exploit niche marketing possibilities.

\section{DISCRIMINATING BISEXUALS}

The question of making gender and sexual distinctions is related to the question of making distinctions between art and commercial entertainment. High art is exclusive, the province of the minority presumed to know, a clique comprising individuals with discriminating taste and knowledge of tradition. Entertainment on the other hand, is the property of everyone; its ease of access encourages promiscuous, excessive con- 
sumption. Representations of bisexual desire often appear paradoxical because bisexuality is both "low" and "high." Bisexuals are characterized by an inability to make distinctions at all: they are the "erotic gluttons" (Weinberg, Williams, and Pryor, 1994, 117) who are interested in "Anything That Moves," a formerly pejorative phrase reclaimed as the title of a bisexual magazine that originated in the San Francisco Bay area in 1991. Bisexuals also possess the power to make the most discriminating choices, however, by virtue of having refused no experience and of having ruled out pre-existing, normative classification schemes. These assumptions underlie conventional views on sexualities, including biphobic perspectives, and may be exploited for the purposes of celebrating or condemning bisexuality.

The conflation of bisexuality and Freud's polymorphous perversity informs both aspects of this binary formula. Freud declared that, before one is capable of making socially appropriate sexual distinctions, one makes none at all. Relying upon Freudian-based assumptions leads to representations of bisexuals as immature, indiscriminate, and potentially treacherous due to their inability to distinguish right from wrong, good from bad, male from female, or normal from deviant. However, because bisexuals are not limited by traditional categories and are imagined to privilege experience for its own sake, they may be in a better position to understand sexuality, to make distinctions on the basis of more and better information. Furthermore, imagined to be immune to emotional attachment and monogamy, bisexuals may be highly cultivated predatory loners without responsibilities to a community. This specter of the bisexual is coincident with theories of bisexuality as merely perfomative, as existing only in the form of sexual acts rather than as an identity that encompasses but also outlives performance.

This dichotomy of too little/too much discrimination has recently found expression in several films that align bisexuality with art and aesthetics. Several mainstream and independent films associate bisexuality with art, a realm of cultural production similarly beset by questions of too little or too much discrimination. Art is simultaneously the realm of creative free expression and a marketplace that commodifies and categorizes art according to binary distinctions, including high/low, traditional/avant garde, and art market/mass culture. The remainder of this essay looks at the link between art and bisexuality in four contemporary films: The Wonder Boys (2000), Before Night Falls (2000), Chasing Amy, and High Art. I focus on the bisexual women in the latter two texts because they distinguish themselves from the former two films through their central thematic concern with the "problem" of women's bisexual- 
ity, whereas the former treat male bisexuality almost incidentally, though in some highly predictable ways. The films that purport to be about women are in fact about bisexual desire and its erasure of distinctions.

\section{BISEXUALITY AND AESTHETICS}

Bisexuals often are identified with an over-developed aestheticism, a common rhetoric for gay masculinity as well. In Vice Versa, Marjorie Garber cites popular press reports that hint at artistic perversion and devotes a chapter to the connection between aesthetics and bisexuality: Time magazine, for example, printed the following observation in its May 13, 1974 issue:

It has become very fashionable in elite and artistically creative subgroups to be intrigued by notions of bisexuality. (cited in Garber, 1995, 19)

Garber connects that intrigue with the perceived imperative that artists and writers pursue non-normative lifestyles:

It is not surprising to find bisexuality alive and well in artists' colonies and aesthetic subcultures. In Bohemia and the avant-garde, the standard expectation for artists, writers, and cultural innovators has been a style of living that flouted conventions, especially sexual conventions. (105)

Garber observes that the startling phenomenon is not artists' bisexuality but, rather, its effacement: "bisexual lives have been described as everything but bisexual" (195). Garber surveys the sex lives of groups of artists drawn together by shared aesthetic and geographical commitments: Bloomsbury, Taos/Santa Fe, Greenwich Village, and the Harlem Renaissance. In her broad focus on twentiet-century artists, Garber does not tie bisexuality specifically to modernism or post-modernism, and interprets the work and lives of both modern artists and writers (Georgia O'Keeffe, Claude McKay) and postmodern celebrities (David Bowie, Sandra Bernhard) as bisexual. Garber does, however, argue that there is a unique relation between bisexuality and performers: "All great stars are bisexual in the performative mode" (Garber, 1995, 140). "What is pathologized in the clinic is celebrated on the stage and at the 
box office" (Garber, 1995, 142). Garber comments on the genre of the celebrity biography and echoes her central thesis that bisexuality always goes both ways by arguing that the bisexuality among celebrities both thwarts the expectations of coherent narrative the genre entails-the "true life" story-and also provides the "truth that sells"(Garber, 1995, 137).

Just as bisexuality appears to provide both the truth and the means of disrupting that truth, it can also be attached to modernism's avant-garde claims to transcendence of the quotidian and it can embrace postmodernism's promiscuous pastiche of high art and popular culture. In other words, bisexual desire can be deployed to evoke a generic aesthetic sensibility writ large-it can take in both the sublime and the kitch, refusing and making distinctions according to some irregular and perhaps irreverent criteria of value. If bisexuality is understood as collapsing sexual and gender distinctions, perhaps it can be utilized to erode other kinds of distinctions, such as those between high and low art. In his caustic review of Garber's Vice Versa, William Kerrigan points out that bisexuality is subject to tremendous slippage and that Garber treats it as synonymous with postmodernism:

Bisexuality is to be inserted into a particularly glamorous slot of intellectual identity politics. As the excluded middle between homosexuality and heterosexuality, forever disappearing between the stools of binary distinctions, bisexuality is nominated to represent postmodernism. (132)

Yet, because bisexual activism and the historical development of bisexuality within identity politics have lingering ties to sexual liberation movements, it is often situated within a modernist context. According to Ara Wilson, writing in the Columbia Guide to Gay and Lesbian Studies in Culture, Communication, and Media:

From the sounds of it, the new "bisexual movement" may be the latest incarnation of the longing for an existence free from constricting gender and sex classifications. (108)

Bisexuality appears modern and postmodern at the same time because it can be manipulated to express the aesthetic visions associated with each paradigm: the heightened aestheticism and transcendent impulse of modernism and postmodern irreverence about class-conscious and class-bound high art. It is not surprising, therefore, to find that several recent films depicting bisexual men and women present narratives of 
artists and art-making that believe in aesthetic transcendence while simultaneously indicting the "art world" context for its crass commercialism and incestuous politics.

In two recent films that focus on male writers, bisexuality circumscribes characters' possibilities for personal and political commitments, yet bisexuality is not the apparent subject of the films. Rather, making art is the focus: the bisexual characters enable the films to venerate coupled monogamy in service to art, whether the relationships are gay, straight, or Platonic. Furthermore, in both films, sexual ambiguity is synonymous with untrustworthiness. In Curtis Hanson's The Wonder Boys (2000), the literary agent Terry Crabtree (Robert Downey, Jr.) epitomizes a warm and fuzzy, sold-out aestheticism. Terry arrives in Pittsburgh for a college writing conference with Antonia, a transvestite, on his arm; his ostensible purpose is to champion his old friend and client, Grady Tripp (Michael Douglas), a professor at the college. Terry needs to monitor the progress of Tripp's long-awaited second novel, but in reality, Terry is in need of Tripp's faux fatherly guidance as well. Terry's first scene marks him as an object of ridicule-he apparently doesn't realize that the woman on his arm is a transvestite. However, in the next scene, Terry exhibits a predatory interest in James, a troubled star pupil of Tripp's, and abandons Antonia, leaving Tripp to drive her home. Despite Terry's harmless demeanor, a scene in a local bar offers a disturbing scenario of sexual coercion: Terry suggests that he would enjoy having sex with James while James is nearly comatose as a result of a raid on Terry's stash of prescription drugs. Terry's inability to distinguish a woman from a transvestite is cause for comedy, his abrupt abandonment of Antonia hints at his immaturity and self-absorption, and his all-out campaign to seduce James suggests his unsavory impulsiveness.

Over the course of the film, Terry becomes sexually and professionally involved with James, after disclosing that his career is in jeopardy because he hasn't handled an important work since Tripp's first novel. After a series of misadventures that allow Tripp and James to cultivate a father-son relationship, Terry agrees to publish James's first novel as well as a book on American marriage penned by the pompous Head of the English Department. Terry compromises his aesthetic scruples and represents the work of the academic hack in order to restore James, whose misadventures jeopardize his status at the college, to the faculty member's good graces.

Although extremely appealing as played by sexually ambiguous Robert Downey, Jr. (whose star text does more than hint at bisexuality), 
Terry embodies the notion of erotic gluttony and excess (sex, drinking, and drugs). Moreover, his motives are often suspicious; Terry makes aesthetic distinctions and business decisions based on his sexual self-interest. By facilitating the father-son/professor-pupil dynamic between James and Tripp, Terry casts into relief the danger of avoiding family and social responsibilities, the perils of singularity-that is, the danger of not making appropriate social distinctions. Tripp's ability to move beyond the boy wonder status of the film's title is revealed in the final scenes of the film: his productive and reproductive capacities in full evidence. The chancellor, with whom he carried on an affair, is now his wife; they have a child, and he is at work on a new and more promising manuscript than the one abandoned earlier. James, Tripp tells us, has moved to New York to revise his manuscript, under Terry's tutelage.

In a universe practically devoid of women, Tripp's pregnant lover, his young female protege, and a bar waitress supply the counterbalance to male bonding, but function as anchors for male creativity. Salon.com's Andrew O'Hehir makes a useful point: “There's an irritating, faux-naive presumption in Wonder Boys that men write and women deal with them the best they can" (1). Tripp's ability to begin making choices distinguishes him from Terry, who is consigned to the role of "a man desperate for a best seller as a means of preserving his hedonistic literary-pasha lifestyle" (1), as Slate.com critic David Edelstein describes him.

Julian Schnabel's Before Night Falls (2000), a film based on gay $\mathrm{Cu}$ ban writer Reinaldo Arenas's memoir, also features a male bisexual character as untrustworthy and unscrupulous, primarily in political terms. The wealthy playboy Pepe Malas is Ray's first lover who cruises, dumps, and possibly sells Ray out to the authorities in Castro's Cuba. Pepe picks up Ray and two women at the same time and makes advances that Ray initially spurns. After Ray becomes involved with Pepe, they go to a club together, where Pepe abandons him for a woman dance partner with whom he stages an exaggerated pas de deux, humiliating Ray. Soon after the Revolution, Arenas is imprisoned and his books are censored. A group of artists and "deviants" make plans to flee the regime and its criminalization of homosexuality and repression of artistic expression by way of a hot air balloon. The unpredictable and immature bisexual Pepe provides the propane gas to fuel the getaway, though Ray accuses him of being an informer and locks him in a wardrobe. Pepe manages to commandeer the balloon while the others recover from their post-revelry stupor. In one of the most visually 
arresting scenes in the film, Pepe dies in a frenetic and poetic balloon crash.

Unlike Wonder Boys, this film does establish a primary focus on sexuality and, specifically, the way the Castro regime defined homosexuality in opposition to the revolution. However, Pepe never chooses "sides," and, therefore, he is suspected of betrayal. Pepe is neither a Castro revolutionary nor an artist, nor does he move from one status to another. His wealth and his bisexuality are used to signal his purely selfish motives for intermittently aligning himself with the government, then with its abjected artist-intellectuals. In the film's conclusion, Ray, stricken with AIDS, is living in New York with a straight friend, Lázaro Gomes Garriles, who cares for him during the final months of his life. The contrast between Pepe's duplicity and Lázaro's loyalty could not be more explicit. In both Wonder Boys and Before Night Falls, bisexual men are fun loving, unreliable lovers and allies, mainly because they refuse to make the distinctions that presage maturity and trustworthiness. They act as foils for the main characters by refusing to make choices and distinctions, which, in these narratives, is understood as a refusal to grow up.

\section{BISEXUAL WOMEN: HIGH AND LOW, ART WORLD/REAL WORLD}

In contrast to the oblique treatment of male bisexuality in Wonder Boys and Before Night Falls, Chasing Amy and High Art are fascinated by the relation between bisexuality and art. Bisexuality and troubled distinctions are their themes. The differences between the way the four films in this essay treat bisexual men and women recalls film scholar Linda Williams' arguments about the representational strategies of pornographic film. Williams asserts that a "frenzy of the visible" characterizes heterosexual pornography and that it is the result of a desire to make the "dark continent" of women's desire visible to men. In paradoxical logic, whereas women's bisexuality seemed "more natural" to Freud and to certain essentialist ideologies that consider women's emotional bonding as more profound than that of men, it is also perceived as fundamentally anomalous because women are perceived to be less sexually aggressive. In Women and Bisexuality, for example, Sue George reports that the doctrine of the unrestrained male sex drive makes bisexuality appear compatible with masculinity, whereas bisexuality among women connotes “nymphomania” (George, 1993, 33). Women's bisex- 
uality is a matter of fascination in these films, for its "natural" (High Art) and its exceptional status (Chasing Amy).

Furthermore, bisexuality in these two films is synonymous with the production of a specific form of visual art: portraiture. The portrait is rendered as caricature in Chasing Amy and photorealism in High Art. In both films, art materializes desire, expressing the artist's erotic stake in her/his object of love or obsession. So, although bisexuality is closely tied to aesthetics, in fact, the aesthetic process is conceived of as merely a faithful relation to reality-something natural-rather than as a constructive, creative, artificial, and imaginative activity. The bisexual erotic of intertwined identification and desire-the mutuality of similarity and difference-produces a form of representation that denies its own process of construction and can only refer "back" to the "real." Art that cannot be distinguished from reality and bisexual characters with "flawed" faculties of discrimination share a certain fate: an aesthetic and personal dead-end.

\section{CHASING AMY}

Chasing Amy, Kevin Smith's low-budget third feature, was produced by independent film maven John Pierson and debuted at the Sundance Film Festival in 1997. Chasing Amy is Smith's final film in a New Jersey trilogy that began with the successful "guerilla" film Clerks, after which Smith made the much-criticized larger-budget feature Mallrats. Ruby Rich finds Smith's film derivative of New Queer Cinema, an early example of the displacement of the community-based queer aesthetic and its leakage into mainstream representation:

If imitation truly is the sincerest form of flattery, then Chasing Amy (1996) was probably the most sincere product of its season. Not only did Kevin Smith manage a career comeback, but his film managed to draw all the attention in a year when numerous lesbian independent features languished for lack of publicity and audience. (24)

In Chasing Amy, bisexuality is never an overt topic of conversation-the word is never mentioned-despite the fact that its twin protagonists, underground comic-book artists Alyssa and Holden, experiment with and/or fantasize about sex with men and women. Alyssa is a lesbian, a member of a community of lesbians that Holden's best friend Banky re- 
fers to as the "little pink mafia." Alyssa becomes involved with Holden, a straight man, against her better judgment. Initially chagrined by his misreading of Alyssa's interest in him, Holden accepts Alyssa's offer of friendship, but eventually admits that he has fallen in love with her. Alyssa does not relinquish her lesbian sexual identity or embrace a straight identity, even when the two become sexually involved. She does admit that her lesbian friends have ostracized her, however. She becomes emotionally and sexually involved with Holden, only to be castigated by him when he learns she was not a "real" lesbian. When he confronts her about her previous sexual experiences with men and women, she tells him "I was an experimental girl." Alyssa-whom critic Edward Guthmann refers to as a "ludicrous piece of wish-fulfillment" (20)-tells him that she searched for a long time, but found sexual and emotional satisfaction only with Holden.

In a language-based analysis of the film, Peter N. Chumo notes that "pronoun usage distinguishes the unlikely lovers Holden and Alyssa" in terms of their maturity (Chumo, 1998, 14). Alyssa uses pronouns cumulatively: from you and I to we, signifying her commitment to the dyadic relationship with Holden. Holden, by contrast, uses a more inclusive, flexible "we" to refer to his relationship with his best friend Banky or the triadic sexual encounter he ultimately proposes among Holden, Banky, and Alyssa (Chumo, 1998, 14). Chumo argues that the film presents Holden as immature in relation to Alyssa, who has "experimented" and finally discovered what she needs with Holden alone.

What is not made clear in Chumo's analysis, however, is that Holden expresses bisexual desire when he uses that inclusive "we" and when he refuses to choose between identification and desire. Holden devises a plan that will satisfy him-he suggests a three-way sexual encounter among Banky, Alyssa, and himself-a move that reflects his desire to be more like Alyssa, to act on his identification with her and her "experimentation" rather than only acting on his sexual desire for her. "We'll finally be on the same level together, " he tells her. Holden wants to have sex with Banky and Alyssa because that allows him to identify with the more experienced Alyssa-already a sexual partner he desires-and to explore erotic desire with an old friend with whom he has identified through professional collaboration.

Over the course of the film, Holden must re-evaluate his own "normal" sexuality, and that of Banky, because Alyssa's bisexuality poses a problem. Although the two are emotionally and sexually compatible and Holden accepts Alyssa's "former" lesbianism, he is finally unable to make sense of Alyssa's "experimentation." The fact that she had sex 
with two men at the same time in high school forces him to question his own view of sexuality and, more particularly, monosexuality, the strict division of sexual orientation into gay or straight. For Holden, lesbians only sleep with women, so his entire view of their relationship changes when he begins to question the pre-ordained distinctions among gay, straight, and lesbian.

Despite the film's subversive and hip cultural location in the world of underground comics and lesbian bars (a site Holden's best friend Banky enjoys because he can see women relating sexually to one another "without paying for it"), Chasing Amy derives comedy, then tragedy, from dismissing sexual distinctions, from refusing to countenance traditional gender and sexual mores. Holden's anxiety regarding Alyssa's past tortures him and he turns his anger on her. She replies by describing her previous sexual choices as a strategy "to not limit the likelihood of finding that one person to complement me so completely." "You turned out to be all I was looking for," she tearfully tells Holden. Thus Alyssa, the film's most apparently experimental character, is in search of the perfect soul mate. The real "secret" of Alyssa's bisexuality is its absence. Her sexuality rests upon a very traditional foundation in the Platonic notion of the humans as originally hermaphroditic: Alyssa seeks the one individual, man or woman, who is her opposite, her "other half." Smith's film thus creates a space for bisexuality only to foreclose it. The film's focus on Alyssa-its chasing of "Amy"-eclipses Holden's exploration and rejection of his bisexuality. The film endorses that rejection by situating Holden's bisexuality-his ability to blend identification with sexual desire-as an emblem of his immaturity, in contrast to Alyssa's championing of serial monosexuality. The secret of women's bisexuality that the film makes visible is that Alyssa isn't a "nymphomaniac" or "erotic glutton" at all, but, instead, a choosy lover in search of Platonic completion. Holden, on the other hand, isn't permitted to call into question the distinctions between friends and lovers in his own sexual and erotic journey. He must choose from the available monosexual options in order to mature, and, importantly, that choice also involves his art.

Smith's fondness for the fantasy world of comic books is in evidence throughout the film, even as he ridicules its apparent simple-minded caricature. The most obvious example of comic books removing necessary complexity is the character Hooper X, a gay friend of Holden's whose public persona, associated with his comic book, is that of a macho Black militant. At a well-attended panel discussion at a comic book convention, he calls out Black Nationalist slogans associated with 
Malcolm X: "the chickens come home to roost," and "by any means necessary."

Comics are by definition a niche market and a low genre, and the film drives this home with the underground magazine published by Holden and Banky, Bluntman and Chronic, and Alyssa's 'zine, Look Idiosyncratic. Moreover, the cultural circulation of images in comics is compared favorably with other forms of visual culture: pornography (Playboy magazine, referred to as a "stroke book") and kitsch (for \$50, Alyssa buys Holden a painting of a bird hanging in a coffee shop they frequent). A conflict between art and commerce arises when Banky attends a meeting with television network executives who want to turn the comic into a televised cartoon. Holden repeatedly fends off that commercial venture, despite Banky's interest in "selling out."

The tension between art and entertainment-and Smith's need to validate comics as both-is played out on several levels in the film. First and foremost is the hierarchy of artist and fan. After a fan enthusiastically refers to Bluntman and Chronic as "Bill and Ted meet Cheech and Chong," Holden responds that he thinks the comic more closely resembles "Rosencrantz and Guildenstern meet Vladimir and Estragon," reflecting an acquaintance with major modern dramatists Tom Stoppard and Samuel Beckett. The fan is unaware of the cultural gulf, however. The most vicious insult is reserved for Banky. Another fan derisively refers to Banky, who is an "inker," as "just a tracer" and scoffs at the talent required for such work, inciting a fistfight. Banky is associated with lowbrow culture even within the comic milieu-he presses Holden to consider the television deal. In the epilogue-a scene at the underground comic convention one year after Holden and Alyssa break up-Holden and Banky have begun new comics on their own. Banky creates Baby Dave, which features an immature, id-like character. It contains the raunchy humor he knows will attract a mass audience: "big bucks are in dick and fart jokes." If Alyssa's refusal to make sexual distinctions is based on her desire to find the one person to complete her, then Banky's refusal to make proper aesthetic distinctions is based on his greed and desire for recognition.

Finally, the film's erosion of distinctions on the level of sexuality is matched by a collapse of aesthetic distinctions, but the latter carry with them far less dire consequences. The three comic-book artists are successful, after they mature as artists and recognize that their art is merely a vehicle for the recirculation of cultural artifacts they find around them. Holden based the characters Bluntman and Chronic on his acquaintances Jay and Silent Bob, and he has paid for the use of their likenesses, 
their branded identities. His creativity was a sham. Reality's intransigence is brought home by the fact that Holden's new comic is entitled Chasing Amy, and it is entirely his creation-that is, he financed it, drew it, and wrote it. But the title refers to Silent Bob's lost love, and the cover of the comic strongly hints that the narrative is a rehash of Holden's relationship with Alyssa. So, Holden's assertion of his own identity as an artist-his attempt to break out of the hierarchy of commerce and art, to explore his own creativity without Banky-is compromised by his reliance upon others and dependent upon his learning the lessons of appropriate discrimination. Alyssa has moved from producing Look Idiosyncratic to Idiosyncratic Routine-revealing the predictability surrounding the supposed uniqueness that characterizes her sexuality. Her idiosyncrasies (and her bisexuality) exoticize her for Holden, but do not in fact challenge normative sexual distinctions: she becomes the elusive object of desire, objectified further in Holden's new comic book.

\section{HIGH ART}

Like Chasing Amy, Lisa Cholodenko's directorial debut, High Art, premiered at the Sundance Film Festival, where it won the Waldo Salt screenwriting award. The film was selected for Director's Fortnight at Cannes and also won the Gay and Lesbian Alliance Against Defamation (GLAAD) media award for outstanding film. Much of the publicity surrounding the film was devoted to actress Ally Sheedy's performance as has-been lesbian photographer Lucy Berliner: Sheedy won the Los Angeles Film Critics and the National Society of Film Critics awards for best actress. "When the prospect of a comeback is dangled before this character, it's as if Sheedy herself were being resurrected as a viable performer," one critic writes (Hartl, 1).

Ruby Rich writes that the film moved beyond the New Queer Cinema paradigm, partly because it refused to celebrate gay and lesbian lives and, instead, depicted a subcultural milieu overshadowed by drug addiction:

Cholodenko's High Art defied all the prior taboos of contemporary lesbian cinema by showing the dark side of lesbian society: cutthroat ambition and opportunism, infidelity, drug addiction. The film charted new territory and did so brilliantly. (24) 
The plot of the film is about comebacks and second chances. Lucy Berliner, a photographer who left the high stakes New York art world, is "re-discovered" by her downstairs neighbor, Syd, a young, ambitious assistant editor at Frame magazine. Lucy's hiatus has been devoted to indulging her addiction and her lover Greta, a former actress featured in the films of New German Cinema enfant terrible, director Rainer Werner Fassbinder. Greta and Lucy's apartment is aglow with the saturated reds, greens, and browns of Fassbinder's films-an atmospheric hangover that explains a great deal about Greta's psyche and the last several years of Lucy's life with her. When Lucy and Syd become professionally and personally involved, the twin forces of heroin addiction and duty to Greta imperil Lucy's project-a photo-essay for Frame, edited by Syd-and the developing relationship.

Seeking to explore an intergenerational affair where sexuality is not the primary concern (Weir, 1), Cholodenko nevertheless draws upon at least one familiar trope of lesbian representation: the vampire. The director states in an interview that "[Lucy has] got a huge dependency problem in a pretty vampiristic love situation" (Neff, 1998, 80). The parasitic Greta and Lucy's heroin habit sap her talent and energy; Syd, it first appears, may be capable of feeding rather than draining her. While it is true that lesbian sexuality is not a central concern in the film-this is not a coming-out narrative-bisexuality is, because Syd's role as a potential savior for Lucy is undermined by her refusal to make distinctions or to choose identification over desire. Syd is a threat to Lucy and her bisexuality occupies the center of the unfolding narrative.

Syd is drawn to Lucy's apartment upstairs because of a plumbing leak. When they inspect Lucy and Greta's bathroom for the source, Syd notices Lucy's photographs hanging there. They are portraits of Lucy's friends that Syd describes as compositionally "skillful" yet "spontaneous," likening the work to "Barthes whole conception of photographic ecstasy." Syd's discursive enthusiasm hints at her training in Critical Theory-a fact disclosed during an earlier conversation with an envious secretary at Frame who dismisses Syd's degree as "pretty cerebral, huh?" and returns to her Penguin classic novel.

Syd's bisexuality is tied to her solipsistic professional ambitions-she clearly has more in common with the secretary than with the editors-and her fascination with Lucy's art and Bohemian lifestyle. That Syd both identifies with Lucy and desires her is made explicit through her experimentation with heroin and through her usurpation of Lucy's dialogue and emotions. Lucy tells Syd that she gave up photography because "there just stopped being a line between me and work. I felt pi- 
geonholed." Later, after her live-in boyfriend James accuses her of having an affair with Lucy, Syd tells him that she feels pigeonholed. Syd has utilized the complaint of "pigeonholing" Lucy discussed in the context of expectations surrounding her artwork to terminate a personal relationship, to refuse a certain sexual classification. Soon after, Syd ends her relationship with James and pursues Lucy, but her motives are clearly mixed; the entangling of personal and professional continues.

In another scene, identification and desire are conflated in a moment of triangulation: Syd usurps Lucy's position after Greta has overdosed and is passed out in the bathtub. Syd performs mouth-to-mouth resuscitation on Greta a few minutes after she and Lucy have shared a kiss, acting as a relay between the two older women, which sparks Greta's anger. Neither Syd's fresh blood or breath is able to "revive" Greta or Lucy, however. Although Lucy's new photographs eventually do appear on the cover of Frame, securing Syd's future, Syd's intervention in the dynamic between Lucy and Greta is anything but salvific.

In fact, Syd serves her own professional needs first and foremost. Renfreu Neff calls the film a

most insightfully orchestrated commentary on the arrogance and hard-ended hypocrisy of the media, where nothing is so intimate or so rarified that it can not be manipulated and corroded for mainstream consumption. (Neff, 1998, 80)

The catalyst in this case is Syd: while she does not intend to exploit Lucy and her work as others have done in the past, she does just that. Her steadfast devotion to Lucy is fueled by desire but ultimately controlled by a deadline for Frame magazine. Lucy is drawn to Syd's ambition; she craves Syd's adulation as a welcome change from Greta's resentment and dependency. Yet Syd is just as dependent upon Lucy's and misconstrues Lucy's professional and personal needs. "[The people at Frame] don't want to trap you, they want to support you," Syd tells her, though Syd herself is in the midst of both trapping and supporting Lucy. Syd suggests that she and Lucy book a room at the Chelsea and set up photo shoots, but Lucy-about to try rehab and to split with Greta-responds that she doesn't work that way. Her portraits are immediate, as Syd had earlier noted. They are not staged. They reflect something "real" about Lucy's life; hence, her successful published book of photographs of Greta and their friends. Syd is intent upon meeting the deadline, oblivious to the fact that Lucy is on the brink of several major life transitions. 
The Frame editors-disdainful purveyors of high art-are interested in Lucy's work precisely because of its exotic appeal. Her "lesbian lifestyle" will make for a provocative cover, a case of high art's appropriation of alternative cultures, in this case, drug and sexual subcultures. The haughty Dominique, a former secretary at Interview who has risen in the ranks at Frame, talks with Syd and Lucy at a lunch meeting about "a certain cultural currency that we would like to explore" by commissioning Lucy's photo essay. Dominique mentions, "revisiting old themes, an examination of friends . . . life"; in other words, she directs Lucy to revisit the near-documentary portraiture of Lucy's earlier book. When Lucy submits older photos as well as recent shots she has taken of Syd during their weekend away from the city, she tells Syd "They wanted me to examine my life. That's it right now. It's about you. I'm thinking about you." Dominique is appalled by the older work-the photos are "without context" and "completely flat"-and drawn to the recent photographs of Syd. She asks Syd if she is Lucy's sitter or her lover before she agrees to publish the photographs. In other words, the doyen of art-world discrimination is more interested in the "real" and personal context of the work than in its formal qualities.

Finally, Syd's inability to distinguish professional and personal interests leaves her bereft. Lucy returns to New York but overdoses the day before her issue of Frame is released. What Syd attempted was to identify with and to desire Lucy. She wanted to see the world as Lucy saw it; to identify with the aesthetic eye of the photographer. The film's visual system suggests Syd's desire to do so. The opening scenes are extreme close-ups of Syd's eye and a slide she is looking at late in the day, before she leaves her office, anonymous and unseen. Her perusal of the photos Lucy submits for the cover is a visual rhyme with that opening scene. Syd has learned to see differently. But mostly what she has learned to see differently is herself. Syd's relationship with Lucy changes her vision: Syd sees differently and is seen differently. She cannot imagine, however, that she shares Lucy's perspective on the world. At the film's conclusion, she is confronted with images of herself that may now be characterized as "without context" and "completely flat." Lucy's art and Syd's career-including the development of her aesthetic vision-are both dead-end propositions.

Ruby Rich argues that the film appeals to an "American affection for upstairs-downstairs dramas" and that

the box office triad of high art, rough trade and a tragic death never fails, however queer the particular application. (Rich, 2000, 24) 
High Art certainly displays all aspects of that triad: Syd's workplace mimics the highly refined, insular, hierarchical art world; the druggy surrealism of Lucy and Greta's parties supplies the rough trade, and Lucy's overdose is an abrupt and devastating tragedy. But the film also proposes that those boundaries of high and low, upstairs and downstairs, ought not to be traversed. Undermining any distinctions may lead to the erosion of all distinctions.

The distinction between art and reality in High Art is questioned, as it is in Chasing Amy. Film critic Roger Ebert makes much of the veracity of the drug-besotted world of Syd's upstairs neighbors:

These people really seem to be living here. They suggest a past, a present, a history, and a pattern that has been going on for years. Their apartment, and how they live in it, is as convincing as a documentary could make it. (Ebert, 1)

Lucy's talent as a photographer-her skills at composition and immediacy-are similarly reduced to the moment, to her emotional connection with her subjects, to her unwillingness to establish boundaries. Lucy's photos of Greta and Syd are exquisite because of her feeling for the camera's object: but the magazine editors find them valuable because they depict "real" lesbians.

The central theme of the art world's exploitation of artists is inextricably bound to Syd and to her bisexuality: Syd is the channel through which Lucy becomes vulnerable again to the expectations of commodified art making.

Syd is unable to distinguish between her romantic and her mercenary feelings for Lucy-or to separate her desire to be Lucy from her desire to have Lucy. At the film's conclusion Syd has no community, no friends, and exhibits an ambivalent relation to her work and her sexuality, as she clutches the Frame magazine that features her own face. The final image is one of extreme narcissism and solipsism, the consequence, it would seem, of Syd's refusal to choose.

\section{CONCLUSION}

In the films I examine in this essay, making distinctions is a troubled process, in the realms of sexuality and art. In Chasing Amy, Alyssa is idealized not because of her sexual experimentation; to the contrary, her appeal derives from an initial exoticism that masks her strictly defined 
dyadic boundaries. She seeks her other half. Syd's bisexuality is the central problem of High Art because her identificatory and sexual investments in Lucy rewrite Lucy's experiences with the commercial art world and her lover Greta. Syd's inability to choose between identification and desire makes Lucy vulnerable and compromises career aspirations, aesthetic inspiration, and erotic possibilities for both women.

The affiliation between bisexuality and art in these films reflects several paradoxes: as an erotics of refusing distinctions, bisexuality acts as a metaphor for the breakdown of traditional gender and sexual categories and for the promiscuous blending of high art and low entertainment. Yet bisexuals are subjects presumed to know; experimental, and, therefore, experienced, they are better equipped to make distinctions between and among sexes and genders (though not necessarily according to conventional classification systems).

Furthermore, a paradox regarding women and bisexuality is apparent in these films. Bisexuality in women is "natural" according to Freudian and other theories of gender difference that endow women with qualities of nurturance and the pairing of emotional and erotic attraction. Yet the sexual insatiability conventionally associated with bisexuality is anathema to the representation of women in those theoretical paradigms. In these films, bisexual women are erotic anomalies (Banky tells Holden he is much too conservative to be Alyssa's lover, for example) or conventional toadies (Greta calls Syd "the teenager") and women's bisexuality shapes the central conflict. Holden seeks to understand his own bisexuality but is prevented from doing so because Alyssa is no longer "experimental." Lucy misrecognizes Syd's passion (for Lucy and for the career opportunities it promises) as compassion. Finally, both Holden and Lucy explore their eroticism through art, but their work is circumscribed by its relation to the real, by a lack of distinction between creativity and reality. Holden writes a comic book about Alyssa that is borrowed from his uncredited collaborator, Silent Bob. Lucy's Frame cover essay is the last work she will produce, and prominently features Syd as the object of her visual and emotional desire.

I would argue that the connection between art-making and bisexual fluidity in these films reflects an anxiety that derives from the location of queer film at the present moment. As Ruby Rich notes, New Queer Cinema is no longer a community-based project; queer representation is not based upon any necessary connection to the real in terms of writers, actors, directors, etc. Queer representations are part of high and low art films, avant garde, underground, mainstream, and kitsch. Independent and industry films as well as television explore and exploit queer char- 
acters and narratives. The various bisexual dynamics in these films enact fears associated with the breakdown of New Queer Cinema distinctions: fears that representations of queerness will not be the province of "real" queers, and that queer cinema will evolve as merely one more niche market. It is no surprise that bisexual women occupy center stage: they not only defy conventions of monosexuality, but also challenge gendered distinctions that cast men as sexual and women as emotional gluttons. The films use art to frame the frenzy of the visible bisexual woman.

\section{REFERENCES}

Bordwell, David, Janet Staiger, and Kristin Thompson. The Classical Hollywood Cinema. New York: Columbia UP, 1986.

Chumo, Peter. "Pronouns Games in Chasing Amy," Creative Screenwriting 5.1 (1998): 12-14.

Ebert, Roger. "High Art." Chicago Sun Times. www.suntimes.com/ebert/ebert_ reviews/1998/07/070301.html. 9/15/2000. . "Chasing Amy.” Chicago Sun Times. www.suntimes.com/ebert/ebert reviews/1997/04/104803.html. 9/15/2000.

Edelstein, David. http://slate.msn.com/MovieReview/00-02-25/MovieReview.asp. $3 / 15 / 2001$

Eiselin, Gregory. "Sentimental Discourse and the Bisexual Erotics of Work," Texas Studies in Language and Literature 41. 3 (Fall 1999): 203-35.

Garber, Marjorie. Vice Versa: Bisexuality and the Eroticism of Everyday Life. New York: Simon and Schuster, 1995.

George, Sue. Women and Bisexuality. London: Scarlet Press, 1993.

Guthman, Edward. “'Amy' Eludes 'Clerks' Director: Low budget boy-gets-lesbian romance," San Francisco Chronicle. www.sfgate.com/cgi-bin/arti...7/04/11/dd18269. DTL\&type=printable 9/15/00.

Hartl, John. "Messy Endings.” film.com. http:/film.com/film-review/1998/10626/ 109/default-review.html. 9/15/2000.

Kerrigan, William. "Bisexual Identity Politics," Raritan 16.2 (1996): 131-9.

Khoury, George. "Beyond New Jersey: Interview with Kevin Smith" Creative Screenwriting 4.2 (1997): 31-6.

Miller, Jonathan. "Clerks: Smells Like Number Two." Creative Screenwriting 3.3 (Winter 1996) 93-5.

Neff, Renfreu. "Film Comments: Carla's Song and High Art," Creative Screenwriting 5.5 (1998): 46, 80.

O’Hehir, Andrew. "Wonder Boys.” http://www.salon.com/ent/movies/review/2000/ 02/25/wonder 3/19/2001.

Pramaggiore, Maria "Straddling the Screen: Bisexual Spectatorship and Contemporary Narrative Film," in RePresenting Bisexualities: Subjects and Cultures of Fluid Desire, ed. Donald E. Hall and Maria Pramaggiore, 275-92. New York: NYU Press, 1996. 
Rich, B. Ruby. "Queer and Present Danger," Sight and Sound 10.3 (March 2000): 22-25.

Rust, Paula. Bisexuality and the Challenge to Lesbian Politics. New York: NYU Press, 1995.

Weir, Emily Harrison. "High Art." The Valley Advocate. wysiwyg://245/http://www. newmassmephtml?code_wma\&db=fil_rev\&ref=1114. 9/15/2000.

Weinberg, Martin S., Colin J. Williams, and Douglas W. Pryor. Dual Attraction: Understanding Bisexuality. New York: Oxford UP, 1994.

Williams, Linda. Hard Core: Power, Pleasure, and the "Frenzy of the Visible." Berkeley: University of California Press, 1999.

Wilson, Ara. The Columbia Reader on Lesbians \& Gay Men in Media, Society, and Politics, ed. Larry P. Gross and James D. Woods. New York: Columbia UP, 1999. 